\title{
The Epistemic Value of Deep Disagreements
}

\section{KIRK LOUGHEED}

\author{
Department of Philosophy \\ McMaster University \\ Hamilton, $\mathrm{ON}$ \\ lougheek@mcmaster.ca
}

\begin{abstract}
In the epistemology of disagreement literature an underdeveloped argument for non-conciationism is based on the idea that there are epistemic benefits to be gained from disagreement. Such benefits are unobtainable if an agent conciliates in the face of peer disagreement, at least within inquiry-related contexts. In argumentation theory a deep disagreement occurs when there is a disagreement between framework propositions. I argue that deep disagreements can lead to epistemic benefits, at least in the context of inquiry. Whether or not rational resolution is possible in cases of deep disagreements, their existence turns out to be epistemically beneficial.
\end{abstract}

Résumé: Dans la littérature sur l'épistémologie du désaccord, un argument sous-développé pour une approche non conciliatoire se fonde sur l'idée qu'il y a des bénéfices épistémiques à tirer du désaccord. De tels bénéfices sont impossibles à obtenir si un agent se concilie face au désaccord avec ses pairs, du moins dans les contextes liés à la recherche. Dans la théorie de l'argumentation, un désaccord profond se produit lorsqu'il y a un désaccord entre des propositions cadres. Je soutiens que des désaccords profonds peuvent mener à des avantages épistémiques, du moins dans le contexte de la recherche. Que la résolution rationnelle soit ou non possible en cas de désaccord profond, leur existence s'avère être bénéfique sur le plan épistémologique.

Keywords: epistemology of disagreement; peer disagreement; deep disagreements; framework propositions; Fogelin

\section{Introduction}

Conciliationists (revisionists, conformists, steadfasters) hold that when an agent becomes aware of epistemic peer disagreement over her belief that $P$, she is rationally required to revise her belief that $P$ (Ballantyne 2014, Christensen 2007, 2014, Elga 2007, Feldman 
2007, Matheson 2015a). Some hold that equal weight should be given to her epistemic peer and hence she should suspend judgment about whether $P$. Others hold that she needs to lower her credence that $P$. Regardless of the specific revision requirements all conciliationists agree that peer disagreement constitutes a defeater (if only partial) to the agent's rational belief that $P$. Nonconciliationists (anti-revisionists, non-conformists), on the other hand, believe that the agent need not revise her belief that $P$ when she becomes aware of epistemic peer disagreement (Bergmann 2009, Elgin 2010, Kelly 2005, van Inwagen 1996). While conciliationism and non-conciliationism occupy the two main positions in the literature, some have defended middling views in which the agent may or may not be required to revise her belief that $P$, depending on the specific details of the case (Lacky 2010a, 2010b, Kelly 2010). ${ }^{1}$

There are important questions about the nature of epistemic peerhood. If epistemic peers need to be exact cognitive and evidential equals then there are no epistemic peers in the real-world (King 2012). After all, it seems unlikely that two agents ever share exactly the same evidence (Sosa 2010). It's also just as unlikely they share exactly the same cognitive resources (King 2012). But cognitive and evidential asymmetries between opponents can be used to explain why they disagree in the first place. The goal of the epistemology of disagreement literature is to understand how to react to a disagreement when such explanations are not in the offing. Still, I suggest that the force of epistemic peer disagreement can be maintained when one reflects on the fact that she often doesn't know whether her opponent is in an inferior (or superior) evidential or cognitive situation to herself. Whatever the correct understanding of epistemic peerhood is, I will assume throughout the rest of this paper that there's an understanding of the concept such that the conciliationist challenge can be generated. ${ }^{2}$

\footnotetext{
${ }^{1}$ Kelly 2010 does not provide any criteria for how to weigh the second-order evidence or disagreement, but he says he it must count as a part of one's total evidence.

${ }^{2}$ Siegel 2013 is a rare instance of connecting the epistemology of disagreement literature with argumentation theory. Much of his paper focuses on the issue of peerhood.
}

(C) Kirk Lougheed. Informal Logic, Vol. 38, No. 2 (2018), pp. 263-292. 
To summarize the vast and ever-growing literature on the epistemology of disagreement any further would take us beyond the scope of my project. Rather, I will focus on an underdeveloped argument against conciliationism. I argue that an agent is rational to continue to believe $P$ in the face of disagreement if she reasonably believes that there are epistemic benefits in the offing if she continues to believe $P$. I support this claim by appealing to real-world examples, empirical evidence (including psychological evidence), and the argumentative theory of reasoning. The argument I develop has interesting connections to Deep Disagreements which have been explored in Argumentation Theory. Deep Disagreements are sometimes understood as unresolvable disagreements between framework propositions. I argue that if fundamental frameworks are responsible for agents' epistemic preferences (e.g., the epistemic risks she is willing to take, which and how much she values different theoretical virtues), then there are epistemic benefits in the offing from the existence of framework propositions. Whether disagreements between framework propositions are rationally resolvable, I suggest that they should be embraced as beneficial to inquiry. I thereby develop an under-examined argument against conciliationism and show how it applies to deep disagreements in argumentation theory.

\section{The epistemic benefits of peer disagreement}

\subsection{The Benefits to Inquiry Argument}

In this section I present the Benefits to Inquiry Argument which defends a limited form of non-conciliationism. Here's the argument in premise/conclusion format:

The Benefits to Inquiry Argument:

(1) Agent $\mathrm{S}$ reasonably believes proposition $P$ within research context $R$, prior to her becoming aware of epistemic peer disagreement about $P$.

(2) If agent $S$ reasonably believes that there are future epistemic benefits to be gained from continuing to believe proposi- 
tion $P$ in the face of epistemic peer disagreement within research context $R$, then $S$ is rational to be a nonconciliationist about $P$ in the context of $R$.

(3) $S$ reasonably believes that there are future epistemic benefits from continuing to believe $P$ within the context of $R$ in the face of peer disagreement about $P$.

Therefore,

(4) Non-conciliationism is rational with respect to $S$ 's belief that $P$ within the context of $R$.

Premise (1) is the claim that an agent must have strong first-order reasons for her belief that $P$ prior to her awareness of peer disagreement about $P$. She can't believe $P$ without evidence, or in the face of counter-evidence, simply by gesturing at future epistemic benefits. The conditional in premise (2) represents the main claim of the argument. I'm going to assume that it's the antecedent, rather than the consequent of the argument that's controversial. I'm also going to assume that the consequent follows from the antecedent. If $S$ really could somehow reasonably believe that epistemic benefits are in the offing within a research context, then she would be rational to remain steadfast. So it is premise (3), the antecedent of (2) that needs defending. In what follows I offer reasons for thinking that (3) is often true, at least within research contexts.

\subsection{Examples in support of (3)}

There are numerous examples that support the truth of (3) in research contexts. Consider the case of Ignaz Semmelweis and bacteria. In the $19^{\text {th }}$ century, hospitals in Europe and America were disease and death-filled places. Childbirth in hospitals by male doctors replaced home births with midwives (Downs 1982, p. 227). But this greatly increased cases of puerperal fever and while it "had long been known in the medical profession...its causes remained a dark mystery" (Downs 1982, p. 228). Ignaz Semmelweis (18181865) was a physician who became concerned with discovering the cause and prevention of puerperal fever which contributed to mortality rates of over $20 \%$ among pregnant women. Against the medical consensus of his day, Semmelweis became convinced that there 
was a way to prevent puerperal fever (Zoltán 2014). He began to observe a connection between rates of the puerperal fever and medical students who had been involved in medical procedures, including examining corpses, before child delivery. When he ordered that all medical students wash their hands in chlorinated lime before child delivery, cases of puerperal fever dropped in his division to $1.27 \%$.

Semmelweis' ideas were, however, generally met with scepticism and hostility from the medical community. Semmelweis published his findings in a book called The Etiology, Concept, and Prophylaxis of Childbed Fever (Semmelweis 1861). But though

[h]e sent it to all the prominent obstetricians and medical societies abroad...the general reaction was adverse. The weight of authority stood against his teachings. He addressed several open letters to the professors of medicine in other countries, but to little effect (Zoltán 2014).

Eventually, Semmelweis experienced a mental breakdown, partly due to his frustration with not being able to convince any of his peers about the truth of his ideas.

Semmelweis faced overwhelming peer disagreement about his belief in the causal connection between hand washing and mortality rates. During his lifetime it was impossible to prove the connection because bacteria remained undetectable. But surely Semmelweis was rational to remain steadfast in his belief. If conciliationism is true, then Semmelweis would have had to revise his beliefs about the connection between hand washing and mortality rates. He would have had to either give up his belief in the causal connection or reduce his credence. And given that so many of his peers disagreed with him, he would have had to greatly reduce his confidence in the connection between hand washing and the fever. He probably would not have written his book or defended his ideas with such vigour. While Semmelweis suffered greatly, he is in many ways an epistemic exemplar. By remaining steadfast in his beliefs about hand-washing the group (i.e., the medical community, but in this case all of also humanity) benefitted in the long term from his continued and rigorous defense of his ideas in the face of disagreement. The Semmelweis case is a clear example of how remain- 
ing steadfast in the face of peer disagreement can lead to positive epistemic results for the group in the long term. It also led to at least some short term benefits given that infant mortality rates dropped in his division. ${ }^{3}$ The epistemic benefits were gained because Semmelweis turned out to be right and all of his or peers who disagreed with him were wrong. The benefits of handwashing wouldn't have been discovered if he had not so tenaciously defended his case, something he would likely not have done had he conciliated to his peers.

One might object that it wasn't the future epistemic benefits which justified Semmelweis in remaining steadfast. It was simply that Semmelweis assessed the first-order reasons about the connection between hand-washing and mortality rates correctly, while his opponents failed to assess the same evidence correctly. Semmelweis was rational, and his opponents were irrational. ${ }^{4}$ But this analysis begs the question against the conciliationism. Part of the sceptical pressure generated by conciliationism comes from the claim that Semmelweis would need a dispute independent reason for remaining steadfast. He would need such a reason in order to justifiably believe he is right and his opponents were wrong. Likewise, he could have avoided the challenge by denying that those

\footnotetext{
${ }^{3}$ Indeed the discovery that puerperal fever is contagious was marked by fundamental disagreements in America too. For instance, in 1875 Alexander Gordon speculated in A Treatise on the Epidemic of Puerperal Fever that there was a connection between who was delivering the child and whether they got the fever. However, "[m]any of the leading doctors, medical school teachers, and nurses of the period, on the other hand, ridiculed the notion that they might be guilty of transmitting the deadly disorder" (Downs 1982, p. 228). Later in 1843, Doctor Oliver Wendell Holmes published a paper titled "The Contagiousness of Puerperal Fever" in The New England Quarterly Journal of Medicine and Surgery. This was the first paper in which many physicians in America accepted that the disease was communicable. Holmes remained steadfast in the face of numerous attacks and continued to defend the claim that the fever is contagious. Downs notes that " $[\mathrm{h}]$ is arguments had been prepared with such care that before long they became accepted facts among enlightened members of the medical profession" (Downs 1982, p. 232). These efforts lead to beneficial results and Downs concludes that " $[\mathrm{t}] \mathrm{o}$ Semmelweis... belongs the major credit for our first knowledge of the means to eliminate the horrible pestilence of puerperal fever" (Downs 1982, p. 233).

${ }^{4}$ Thanks to an anonymous referee for bringing this objection to my attention.

(c) Kirk Lougheed. Informal Logic, Vol. 38, No. 2 (2018), pp. 263-292.
} 
who disagree with him were genuinely his epistemic peers. However, neither of these strategies seem as if they were available to Semmelweis. How could he have known that he was assessing the evidence correctly, but his peers weren't? We only know this looking back at the case, but the question we want to know is whether Semmelweis himself was rational to remain steadfast at the time of the disagreement. Also, it seems unlikely that every single doctor or scientist who disagreed with Semmelweis was not his epistemic peer. To claim that only Semmelweis accurately assessed the firstorder evidence, or that he had no genuine epistemic peers is to beg the question against conciliationism. We want to know what is epistemically rational to believe in cases where two opponents disagree, and it isn't obvious that one is mistaken, or they aren't actually peers.

This example isn't meant to be conclusive evidence for (3) with respect to every case of disagreement. It is, however, just one of numerous examples in the history of inquiry where remaining steadfast in the face of disagreement led to epistemic benefits. Consider, for example, Galileo and Heliocentrism, or Charles Darwin and Natural Selection. I also haven't purported to offer strict criteria for when this argument applies to a belief. My point is that we wouldn't want to say that Semmelweis, Galileo, and Darwin were epistemically irrational to believe what they did, even at the time that they believed it.

\subsection{Empirical support for (3)}

\section{a. Superior problem-solving and prediction}

There is empirical support for premise (3). While empirical studies with the epistemology of disagreement explicitly in view have not been conducted, there is at least some empirical evidence on offer that supports the idea behind the claim that remaining steadfast in the face of disagreement yields positive epistemic results. In The Difference: How the Power of Diversity Creates Better Groups, Firms, Schools, and Societies, Scott Page (2007) argues persuasively that in many scenarios, diverse groups are better at problemsolving and prediction making than homogenous groups. This is so even when the homogeneous group consists of more talented indi-

(C) Kirk Lougheed. Informal Logic, Vol. 38, No. 2 (2018), pp. 263-292. 
viduals than the heterogeneous. This finding provides evidence for the claim that there are long-term epistemic benefits to be gained if an agent remains steadfast in her beliefs in the face of peer disagreement. Disagreement contributes to the cognitive diversity that, according to Page, enhances the success of epistemic tasks such as problem solving and prediction. He provides some technical economic models to support his claim that I won't outline in detail here. $^{5}$

Page says his thesis is that "collections of diverse individuals outperform collections of more individually capable individuals" (Page 2004, p. 159) when the following four conditions are met:

Condition 1: The Problem is Difficult. No individual problem solver always locates the global optimum [i.e., best solution].

Condition 2: The Calculus Condition. The local optima of every problem solver can be written down in a list. In other words, all problem solvers are smart.

Condition 3: The Diversity Condition. Any solution other than the global optimum is not a local optimum for some nonzero percentage of problem solvers.

Condition 4: Good-Sized Collections Drawn from Lots of Potential Problem Solvers. The initial population of problem solvers must be large, and the collections of problem solvers working together must contain more than a handful of problem solvers (Page 2004, p. 162).

He claims that while these are not the only conditions when diversity will trump ability, but that when these conditions are met, diversity will always win out. That is, when these conditions are met, a diverse group of problem solvers will always outperform a collection of individually more talented, but homogeneous problem solv-

\footnotetext{
${ }^{5}$ See also James Surowiecki (2004). Surowiecki argues that within certain parameters groups are wiser than individuals. See also Moshman and Geil (1998).

(C) Kirk Lougheed. Informal Logic, Vol. 38, No. 2 (2018), pp. 263-292.
} 
ers (Page 2004, p. 162, 165). Page states that there are many examples where groups of diverse people make almost unbelievably accurate predictions (Page 2004, p. 177). His predictive models show that cognitive diversity matters just as much as ability with respect to prediction. ${ }^{6}$ He claims it is almost undisputed that cognitive diversity improves collective performance when it comes to making predictions (Page 2004, p. 320).

\section{b. Counteracting confirmation bias}

The existence of disagreement can also serve to counteract confirmation bias. For example, Duarte et al. argue that the discipline of social psychology is overwhelmingly politically liberal. It turns out that this widespread agreement likely negatively impacts the research being conducted by social psychologists. This is because liberal values and assumptions are often embedded into research questions and observations. Researchers also tend to only focus on research topics that are likely to reinforce liberal values, while avoiding topics that might support a different political perspective (Duarte et al. 2015). ${ }^{7}$

The well-known phenomena of confirmation bias is that "[p]eople tend to search for evidence that will confirm their existing beliefs while also ignoring or downplaying disconfirming evidence" (Duarte et al. 2015, p. 7). Psychologists have demonstrated that confirmation bias is difficult to avoid in almost any setting. For

\footnotetext{
${ }^{6}$ Page cites many studies about whether identity diversity improves performance. His book culminates in the Value in Diversity Hypothesis which states that "[i]dentity diverse groups perform better than homogeneous groups" (Page 2004, p. 319). This is dependent on the empirical claim as identity diversity is causally connected cognitive diversity.

${ }^{7}$ Duarte et al notes that the existence of cognitive diversity is more important than personal identity diversity for epistemic benefits (Duarte et al, forthcoming; Menz 2012; Williams and O'Reilly 1998). I do not dispute this claim but this is ultimately subject to empirical scrutiny. Duarte et al suggests that the benefits of cognitive diversity are most easily had when "organizations are pursuing openended exploratory goals (e.g., scientific discovery) as opposed to exploitative goals (e.g., applying well-established routines to well-defined problems)" (Durate et al, Cannella, Park and Hu 2008). This implies that the Benefits to Inquiry Argument might be more or less successful depending on the specific research questions being explored.
}

(C) Kirk Lougheed. Informal Logic, Vol. 38, No. 2 (2018), pp. 263-292. 
example, studying critical reasoning only leads to temporary suppression of bias in college students. Academics with high IQs are prone to offer more reasons in favour of their own views, rather than being more open to opposing ideas than lay people with lower IQs and less education (Duarte et al. 2015). Thus, "people are far better at identifying the flaws in other people's evidence-gathering than in their own, especially if those other people have dissimilar beliefs" (Duarte et al. 2015, p. 8; Mercier and Sperber 2011; Sperber et al. 2010).

Psychologists have also explored the positive epistemic impact that a dissenting minority can have on group decision-making. Majority-based decision-making often creates strong pressure for group conformity and thus leads to groupthink (Duarte et al., forthcoming; Fiske, Harris and Cuddy 2004). A dissenting minority is able to disrupt group cohesion norms. This is epistemically beneficial if the group norms in question are problematic. For instance, in the scientific community such minority disagreement is epistemically beneficial because it causes scientists to think more deeply about their research (Duarte et al. 2015; Crano 2012). Thus, "[t]he many benefits of these processes have been borne out by research on minority influence, which shows that the deeper thought produced by dissent can lead to higher-quality group decisions" (Duarte et al 2015, p. 8; Crisp and Turner 2011; Moscovici and Personnaz 1980; Nemeth 1995; Nemeth, Brown and Rogers 2001).

If Duarte et al.'s conclusions are correct, and if those conclusions can be generalized and applied more broadly, then there is reason to think cognitive disagreement is epistemically ideal, especially in research contexts. Confirmation bias is problematic in individual reasoners, but not when they are reasoning as part of a cognitively diverse group where such biases can begin to cancel each other out.

\section{c. Argumentative theory of reasoning}

While the existence of more disagreement is one way to help combat the negative epistemic impact of confirmation bias, there is another account of bias worth exploring. Depending on the evolutionary function of human reasoning there is another way to understand confirmation bias and motivated reasoning which shows humans 
are not actually poor reasoners. This account, if correct, also promotes the epistemic benefits of peer disagreement. ${ }^{8}$ While their view is far from uncontroversial, Hugo Mercier and Dan Sperber have argued in favour of the argumentative theory of human reasoning. This theory claims that the purpose of reasoning is to create arguments intended to persuade an opponent. Arguing serves the evolutionary function of leading to better communication between humans. Mercier and Sperber claim that this theory better explains much of the psychological data on human reasoning, in particular, data that suggests that humans are often poor reasoners (Mercier and Sperber 2011, p. 58-60). ${ }^{9}$ Rather, "[r] easoning enables people to exchange arguments that, on the whole, make communication more reliable and hence more advantageous. The main function of reasoning...is argumentative" (Mercier and Sperber 2011, p. 60). They continue to argue that in order "[f]or communication to be stable, it has to benefit both senders and receivers; otherwise they would stop sending or stop receiving, putting an end to communication itself" (Mercier and Sperber 2011, p. 60). ${ }^{10}$

Mercier and Sperber confirm some of the ideas in Page's work when they suggest that reasoning produces the best results in the context of group discussions. Interestingly, research suggests that if one person in a group knows the truth, then she will almost always be able to convince the other group members of the truth. With Page, they also suggest that group performance is superior to the individual performance of the group's best member. Thus:

[I]n many cases, no single participant had the correct answer to begin with. Several participants may be partly wrong and partly

\footnotetext{
${ }^{8}$ Thanks to Klaas J. Kraay for bringing this to my attention.

${ }^{9}$ Mercier and Sperber explain that a: "trait is an effect of that trait that causally explains its having evolved and persisted in a population: Thanks to this effect, the trait has been contributing to the fitness of organisms endowed with it. In principle, several effects of a trait may contribute to fitness, and hence a trait may have more than a single function. Even then, it may be possible to rank the importance of different functions, and in particular to identify a function for which the trait is best adapted as its main function" (Mercier and Sperber 2011, p. 59).

${ }^{10}$ See also Billig 1996; Dessalles 2007; Kuhn 1992; Perelman and OlbrechtsTyteca 1969; Mercier and Sperber 2017; Sperber 2000; 2001.

(c) Kirk Lougheed. Informal Logic, Vol. 38, No. 2 (2018), pp. 263-292.
} 
right, but the group will collectively be able to retain only the correct parts and thus converge on the right answer. This leads to the assembly bonus effect, in which the performance of the group is better than that of its best member (Mercier and Sperber 2011, p. $63) .{ }^{11}$

On the argumentative theory of reasoning, confirmation bias is a feature of human reasoning rather than a hindrance to accurate human reasoning. When an agent is attempting to convince her opponent of a belief, she should be seeking arguments in favour of her own position rather than her opponent's. This implies that the existence of confirmation bias is to be expected. Many experiments purport to show that when participants are asked to evaluate an argument, they simply defend the position they already believe to be true. Reasoning is employed only to confirm initial intuitions. Mercier and Sperber claim this is exactly what to expect on the argumentative theory of reasoning (Mercier and Sperber 2011, p. 65). Provided that group members can eventually be convinced by the truth, groups are epistemically better off if individual members pursue a single hypothesis on their own rather than many different hypotheses at the same time. Disagreements between peers in a group is epistemically beneficial. ${ }^{12}$

Argumentation leads to better communication which is the purported adaptive advantage behind argumentation. And adaptations work best when they perform the task they evolved to do. This, then, is an adaptive reason to remain steadfast in the face of disagreement (Mercier and Sperber 2011). An agent is better off to let

\footnotetext{
${ }^{11}$ See also Blinder and Morgan 2000; Laughlin et al 2002; 2003; 2006; Lombardelli et al 2005; Michalesen et al 1989; Sniezek and Henry 1989; Stasson et al 1991; Tindale and Sheffey 2002.

${ }^{12}$ Motivated reasoning occurs when an agent proactively seeks arguments in support of her beliefs because they anticipate needing to argue for the beliefs in question. If an agent reflects on the controversial nature of a belief she holds, "[i]t makes sense to look for arguments for our opinions before we find ourselves called upon to state them. If the search for arguments is successful, we will be ready. If not, then perhaps it might be better to adopt a weaker position, one that is easier to defend" (Mercier and Sperber 2011, p. 66). ${ }^{12}$ According to Mercier and Sperber, motivated reasoning cannot be mere wishful thinking since otherwise participants in various studies would dismiss evidence or arguments rather than attempt to undermine them.
}

(C) Kirk Lougheed. Informal Logic, Vol. 38, No. 2 (2018), pp. 263-292. 
her opponents evaluate her arguments. Again, this suggests she should remain steadfast in the face of peer disagreement and let her opponents check her reasoning. ${ }^{13}$

\subsection{Objections}

In this section I briefly address two of what I consider to be the strongest objections to the Benefits to Inquiry Argument.

\section{a. When can an agent rationally believe epistemic benefits are in the offing?}

The Benefits to Inquiry Argument I am defending doesn't purport to offer a criterion to answer this question. This objection is about the practical application of the argument, not the truth of any of the premises. Perhaps the objector will worry that without any practical guidance the argument might serve to license irrational dogmatism. An agent could bootstrap her way to rationality with a vague appeal to future epistemic benefits. In certain cases this argument will rationalize beliefs that turn out to be false. But notice that the argument is situated within research contexts. Nothing in the Benefits to Inquiry Argument exempts a researcher from needing to have strong first-order reasons for holding the inquiry-related beliefs that she holds. Indeed, she couldn't reasonably believe $P$ the propositions over which there is disagreement-without having strong first-order reasons for belief that $P$ in the first place. She can't simply appeal to future epistemic benefits to justify her belief that $P$ if she didn't already reasonably believe $P$. The idea of the argument is that she has first-order reasons for her belief and then encounters epistemic peer disagreement about $P$. Within research contexts she is rational to continue to believe $P$ because of the evidence provided above in defense of premise (3). I don't claim to provide details on what would make a case relevantly and sufficiently analogous to the above examples to justify remaining steadfast. But presumably such cases occur with some degree of fre-

\footnotetext{
${ }^{13}$ This is not to imply, because $\mathrm{x}$ is adaptive that $\mathrm{x}$ is necessarily rational. I am not claiming that one should remaining steadfast because it is adaptive. Rather, given that it is adaptive, it come as no surprise that there are epistemic benefits to disagreement. The argumentative theory of reasoning confirms my hypothesis.

(C) Kirk Lougheed. Informal Logic, Vol. 38, No. 2 (2018), pp. 263-292.
} 
quency. My argument never purports to offer detailed practical guidance, so it's hardly a worrisome objection that it doesn't provide such guidance

\section{b. This method of inquiry licenses irrationality}

A related worry is that the Benefits to Inquiry Argument justifies a method of inquiry which will end up licensing irrationality. ${ }^{14}$ Suppose an agent irrationally believes $P$. She doesn't have good firstorder reasons to believe that $P$. However, further suppose that she believes disagreement and cognitive diversity is generally a good environment under which to pursue inquiry. That is, the method tends to be truth-conducive. Thus, the agent claims that she is rational to continue to believe that $P$ because doing so creates cognitive diversity which is beneficial to inquiry.

The Benefits to Inquiry Argument does not license an agent to believe $P$ in such a scenario. The argument is not licensing a method of inquiry that trumps first-order reasons. Premise (1) of the argument makes this clear. Likewise, the agent herself (and not just the research community) must reasonably believe she will receive the benefits. It's true that the Benefits to Inquiry Argument will promote certain methods and a particular type of research community. But the focus is on whether specific individuals are reasonable to continue to believe a proposition in the face of epistemic peer disagreement. $^{15}$

\section{c. Future benefits are practical reasons, not epistemic reasons}

Richard Feldman and David Christensen seem to anticipate the worry that peer disagreement will pose a threat to the rationality of research. They both argue that future epistemic benefits make it practically rational to continue to pursue a line of research in the face of disagreement, but it's nevertheless not epistemically ration-

\footnotetext{
${ }^{14}$ Thanks to an anonymous referee for prompting me to add this section.

${ }^{15}$ It's an open question whether what's epistemically best for the group can conflict with what's epistemically best for the individual. My focus in this project is the individual and so I won't address this further here.
}

(C) Kirk Lougheed. Informal Logic, Vol. 38, No. 2 (2018), pp. 263-292. 
al to do so (Christensen 2007, p. 216; Feldman 2011; p. 157). ${ }^{16}$ Thus, the Benefits to Inquiry Argument conflates practical reasons with epistemic reasons.

A much-neglected distinction in epistemology helps shed light on the intuition driving this objection. There's a difference between synchronic epistemic reasons and diachronic epistemic reasons. Elsewhere, I have defended the view that diachronic reasons are indeed epistemic (Lougheed and Simpson 2017, p. 157). Epistemologists, historically and presently, focus almost exclusively on synchronic reasons. When Feldman and Christensen defend conciliationism about peer disagreement, they really defend the more specific position that one ought to conciliate right now when faced with disagreement (Matheson 2015a and 2015b). Peer disagreement, then, provides a defeater for an agent's synchronic belief that $P$, not necessarily her diachronic belief that $P$. An all-thingsconsidered rationality will account for both synchronic and diachronic reasons. It will no doubt be controversial as to how to weigh such reasons against one another. For instance, Jonathan Matheson has speculated that there might be no way to combine the two types of reasons in order to have an all-things-considered rationality. He writes that there might be "no all-epistemic-thingsconsidered perspective, but only the disambiguated epistemic perspectives" (Matheson 2015b, 144). Elsewhere, I have argued that, contra Matheson, an all-things-considered account of rationality will give equal weight to both synchronic and diachronic reasons. ${ }^{17}$

\footnotetext{
${ }^{16}$ Christensen writes: “It's quite plausible that knowledge is best advanced by people exploring, and attempting to defend, a variety of answers to a given question. Perhaps, human psychology makes this easier to do when investigators actually have a lot of confidence in the hypotheses they're trying to defend. Certain sorts of inquiry might well work best when a variety of investigators have irrationally high levels of confidence in a variety of pet hypotheses. So there may well be important epistemic benefits to certain patterns of irrational belief. But I would argue that the patterns of belief are no more epistemically rational for all that" (Christensen 2007, p. 216).

${ }^{17}$ See my unpublished manuscript, "All-Things-Considered Epistemic Rationality and Avoiding the Sceptical Consequences of the Equal Weight View."

(C) Kirk Lougheed. Informal Logic, Vol. 38, No. 2 (2018), pp. 263-292.
} 
Discussing this further is beyond the scope of my project here, but this distinction deserves more attention from epistemologists. ${ }^{18}$

\section{d. Future epistemic benefits can be gained from believing falsehoods}

Even if one accepts that diachronic reasons are epistemic, one might still worry that the Benefits to Inquiry Argument justifies cases where believing a falsehood at the synchronic level leads to positive epistemic results at the diachronic level. Suppose a researcher has strong evidence suggesting that her partner has been unfaithful to her. Despite this strong evidence, she continues to believe in her partner's faithfulness. This allows the researcher to avoid emotional and psychological devastation which would prevent her from successful research. Her psychological well-being is essential to her success as a researcher. ${ }^{19}$ The Benefits to Inquiry Argument is not intended to cover these sorts of beliefs. The argument stipulates that it is only concerned with beliefs in research contexts which are its target. More specifically, it is research beliefs within research contexts that the argument is seeking to protect. Proposition $P$ in the premises of the argument is supposed to represent research content.

Likewise, the question of whether the researcher is rational to believe her partner is faithful isn't one over which she encounters epistemic peer disagreement. The purpose of the Benefits to Inquiry Argument is to avoid conciliationism, at least in the scenarios described in the premises of the argument. The objector, however, could simply reformulate the example to include peer disagreement about whether the researcher's partner is faithful. But this does nothing to strengthen the objection. The fact remains that this simply isn't the sort of belief that falls within the scope of the argument.

\footnotetext{
${ }^{18}$ Finally, consider that reasons are not time sensitive from a logical point of view. Reasons are just reasons. There would have to be some principled reason to favour the reasons we have right now versus reasons we will have later. Or, consider the distinction between synchronic and diachronic reasons as one between synchronic reasons indexed to time. Diachronic reasons are just synchronic reasons at a future time $T_{n}$.

${ }^{19}$ Thanks to anonymous referee for prompting me to be clearer on this point. This example is taken directly from the referee.
}

(C) Kirk Lougheed. Informal Logic, Vol. 38, No. 2 (2018), pp. 263-292. 
Finally, it's worth noting that the Benefits to Inquiry Argument is silent on cases like the one described in this objection. Relatedly, it's well-established that clinically depressed people give more accurate self-assessments than those who aren't suffering from depression. It turns out, however, that having a slightly inflated view of oneself is helpful to functioning normally. Indeed, positive selfassessments are probably helpful (if not essential) to the success (and productivity) of researchers. But this has nothing to do with the types of beliefs I'm trying to preserve in the face of conciliationism with the Benefits to Inquiry Argument. The question I'm concerned with is whether the researcher's inquiry-related beliefs are epistemically rational in the face of epistemic peer disagreement.

\section{The value of deep disagreements}

\subsection{What are deep disagreements?}

In this section I examine what argumentation theorists call deep disagreements. I will make some connections to deep disagreements and the Benefits to Inquiry Argument. In a seminal paper on deep disagreements, Robert J. Fogelin argues that genuine argument is only possible when two agents share many common background beliefs. In this sense, then, argumentation is always context sensitive. These shared beliefs provide "the structure within which reasons can be marshaled, where marshaling reasons is typically a matter of citing facts that others already know or of arranging facts in a way that their significance becomes clear" (Fogelin 1985, p. 3). Fogelin continues on to claim that "an argumentative exchange is normal when it takes place within a context of broadly shared beliefs and preferences. I shall further insist that for an argumentative exchange to be normal, there must exist shared procedures for resolving disagreements" (Fogelin 1985, 3). According to Fogelin, then, genuine argument is only possible when two agents share many beliefs in common. When a significant number of beliefs are shared, Fogelin says, the result is a normal (or almost normal) argumentative context (Fogelin 1985, p. 4). He explains that: 
[T] o the extent that the argumentative context becomes less normal, argument, to that extent, become impossible. This is not the weak claim that in such context arguments cannot be settled. It is the stronger claim that the conditions for argument do not exist. The language of argument may persist, but it becomes pointless since it makes an appeal to something that does not exist: a shared background of beliefs and preferences (Fogelin 1985, p. 4-5).

These are deep disagreements and they "cannot be resolved through the use of argument, for they undercut the conditions essential to arguing" (Fogelin 1985, p. 5). In other words, deep disagreements represent disagreement over "underlying principles". They are about a clash of underlying framework propositions (Fogelin 1985, p. 5). For instance, in deep disagreements, opponents could agree on all of the relevant historical and scientific facts about the dispute in question, and yet still disagree (Fogelin 1985, p. 7). Fogelin writes that one might be tempted to think that once such propositions are brought to the forefront of the disagreement they can be rationally evaluated by the disagreeing peers. But this isn't possible because deep disagreements aren't simply about isolated propositions. They represent disagreements over a "whole system of mutually supporting propositions (and paradigms, models, styles of acting and thinking) that constitute... a form of life" (Fogelin 1985, p. 5-6). Different forms of life overlap and crisscross with another such that one could trust a person on a particular topic but not on another topic (Fogelin 1985, p. 6) Fogelin explains that in light of this discussion, there is no obvious way to rationally resolve deep disagreements (Fogelin 1985, p. 6). ${ }^{20}$ He doesn't see how it's possible to adjudicate between competing fundamental framework propositions. He concludes that

[w]e can insist that not every disagreement is deep, that even with deep disagreements, people can argue well or badly. In the end, however, we should tell the truth: there are disagreements, sometimes on important issues, which by their nature, are not subject to rational resolution (Fogelin 1985, p. 7)

\footnotetext{
${ }^{20}$ Fogelin explains that he borrows these ideas from Wittgenstein 1972, p. 608612.

(c) Kirk Lougheed. Informal Logic, Vol. 38, No. 2 (2018), pp. 263-292.
} 
Fogelin's account of deep disagreement is not uncontroversial. For instance Richard Feldman argues that the rational resolution to deep disagreement might be to suspend judgment about the fundamental framework (2005). Harvey Siegel claims that reflections on the nature of epistemic peers can dissolve the problem Fogelin creates (2013). David M. Adams suggests that Fogelin's account is of little practical value since it can't resolve moral dilemmas, in medicine for instance (2005). Peter Davson-Galle agrees with Fogelin that deep disagreements are incapable of rational resolution but denies that they are about frameworks rather than just over isolated propositions (1992). Vesel Memedi suggests that deep disagreements may be resolvable from a third-party perspective (2007). ${ }^{21}$ I won't outline this literature further or attempt to assess it. I suspect that Fogelin (and indeed Wittgenstein) are onto something important, but I won't defend this claim here. Rather, I'm going to explain the epistemic benefits of deep disagreements regardless of whether it is possible that they can be rationally resolved.

\subsection{Deep Disagreements and the Idealized Cases in the Episte- mology of Disagreement}

While Fogelin uses the terminology of 'argument' I think he would intend some of what he says to apply to the disagreements discussed in the epistemology of disagreement literature. There are places where using 'disagreement' and 'argument' interchangeably is inappropriate, but for my purposes I will use them interchangeably. The epistemology of disagreement literature often employs idealized cases to help understand what the appropriate rational response is to peer disagreement. Richard Feldman describes a case of perceptual disagreement between two people about whether the dean is in the quad (2007, p. 207-208). Another perceptual disagreement described by Adam Elga is a dispute about which horse won the race (2007, p. 166-167). Finally, perhaps the most-cited example is David Christensen's story about friends who disagree over how much each owes of the restaurant bill (2007, p. 193). These cases are meant to support conciliationism about disagree-

\footnotetext{
${ }^{21}$ See also Friemann 2005; Lugg 1986; Phillips 2008; Turner and Wright 2005.

(c) Kirk Lougheed. Informal Logic, Vol. 38, No. 2 (2018), pp. 263-292.
} 
ment since it seems obvious that in such cases one ought to revise one's belief (or suspend judgment or lower credence).

Elsewhere I argue, contra Feldman and Christensen, that the lessons from such cases do not provide lessons about how to respond in more complex cases in disagreement (Lougheed 2017, 251-270). I argue that there are two major differences between simple cases and complex cases of disagreement. First, in simple cases there is only one way for agents to revise and maintain a coherent set of beliefs in the face of disagreement, while in the complex cases there are multiple routes to coherence. Second, in the simple cases any normally functioning adult could be expected to have the expertise required to resolve the dispute, whereas in more complex cases special expertise is required.

Consider that the simple cases are clearly what Fogelin would call "normal disagreements". There are enough background beliefs in common between the disputing parties to rationally resolve the dispute. It's less clear that complex disagreements over religion, politics, and morality are what Fogelin would categorize as "normal" as opposed to "deep". This is an interesting connection between the two literatures because if the complex disagreements are "deep" this fact would serve to bolster my argument that lessons from one type of disagreement don't apply seamlessly to other types of disagreement. In other words, how to respond to normal disagreements does not apply to deep disagreements. The former can be in principle rationally resolved, while the latter are not susceptible to rational resolution (at least according to Fogelin).

For those interested in the epistemology of disagreement who recognize that deep disagreements sometimes occur a pressing question becomes: what's the appropriate rational response when an agent who believes $P$ discovers epistemic peer disagreement about $P$, and further discovers that the disagreement about $P$ is deep? One possible response would be to attempt to argue against Fogelin and present a method for rationally resolving deep disagreements. As I've already said, I won't pursue such a project here. Capable Philosophers have taken up and will take up that project. Rather, I want to explore a connection between deep disagreement and the Benefits to Inquiry Argument: Why think that deep disagreements are a problem needing resolution? Why think that 
they pose a threat to the business of argument, the occupation that philosophers so often engage in? There are epistemic benefits to be gained from deep disagreements such that the existence of different fundamental framework propositions may turn out to be epistemically valuable for inquiry.

\subsection{The epistemic benefits of deep disagreement}

Regardless of whether deep disagreements are susceptible to rational resolution, I argue that the existence of such disagreements are epistemically beneficial, at least in research contexts. Below is the application of the Benefits to Inquiry Argument to deep disagreements.

The Epistemic Benefits of Deep Disagreement Argument:

(5) Agent $S$ reasonably believes proposition $P$ within the search context $R$ as a result of her fundamental framework $F$.

(6) If agent $S$ believes $P$ in the context of $R$ as a result of her fundamental framework $F$, then the epistemic benefits of believing $P$ in the context of $R$ are ultimately the result of her fundamental framework $F$.

(7) $S$ reasonably believes that there are future epistemic bene fits from continuing to believe $P$ within the context of $R$ in the face of peer disagreement about $P$ and the epistemic benefits of disagreement over $P$ within the context of $R$ are ultimately the result of disagreement over $F$.

Therefore

(8) Epistemic benefits are ultimately the result of fundamental framework disagreement.

(6) is a restatement of (2) with the additional clause that $S$ 's belief that $P$ is the result of her fundamental framework propositions. With Fogelin, if we understand fundamental frameworks as a set of interconnected propositions then it's easy to see how this applies to a researcher. For instance, a physicist's interpretation of quantum mechanics will depend on what she thinks about a wide host of other issues. Different frameworks will cause researchers to place 
different values on the importance of different theoretical virtues, and to be open to different degrees of epistemic risk (i.e., balance of true beliefs to false beliefs).

(7) is the premise requiring further explanation. An implicit assumption in (7) is that $S$ 's opponent who believes not- $P$ ultimately believes it as result of her holding to a different fundamental framework from that of $F$. This isn't to say that there can't be any overlap between the propositions found in $F$ and the competing framework that has led to the belief not- $P$. Presumably, while Fogelin uses the example of disagreement about abortion as one of a deep disagreement, he will still accept that those who disagree about abortion still agree on the truth value of multiple propositions. For instance, they will still agree about, say, the truth of the theory of gravity. The point is that the different fundamental framework propositions disagree on enough propositions that they are not in what Fogelin terms a "normal" disagreement. According to Fogelin they do not have enough in common for the possibility of ever rationally resolving the dispute.

Finally, within the dialectical context of my argument, the fundamental framework propositions of the two epistemic peers are so disparate that they yield entirely different results about whether $P$ even though they are both within the same research context of $R$. To further bolster this idea, we can stipulate, as Fogelin does, that the two peers have all of the same information with respect to $P$ within the context of $R$. In this case, it's difficult to see how they could even disagree about whether $P$ was within $R$ if they didn't hold competing fundamental frameworks. So, the disagreement over $P$, and hence the epistemic benefits about the disagreement over $P$, are ultimately the result of a disagreement over competing fundamental frameworks. This leads to the conclusion (8), that there are epistemic benefits to be gained from fundamental framework disagreement.

Notice that this argument does not depend on taking a stance as to whether deep disagreements are susceptible to rational resolution. Whether fundamental frameworks can be rationally evaluated with framework independent (and hence value-neutral) standards is not important to my argument. Regardless of the possibility of such rational resolution, I am claiming that there are epistemic benefits 
to be gained from the existence of competing frameworks, at least within research contexts. My argument, then, is silent as to Fogelin's claim about the nature of fundamental framework disagreement. $^{22}$

\subsection{Two Objections}

\section{a. There won't be inter-framework disagreements}

Time constraints prevent me from examining many objections, but I will examine what I take to be two of the most pressing objections to this line of argument. Suppose the Benefits to Inquiry Argument is sound and that one also accepts (7), that $S$ 's belief that $P$ is ultimately the result of $F$. A natural objection is that (7) is false because there won't be deep disagreements within research contexts. There is a minimum amount of agreement required for researchers in a subject area that will negate the possibility of deep disagreements within research contexts. Fogelin's example about abortion is one of fundamental framework disagreement, but it is not within a research context. In other words, how can researchers be inquiring into the same subject if they don't share enough of the same relevant background beliefs?

One might be tempted to respond that the Benefits of Deep Disagreement Argument is research-subject sensitive. In subjects such as philosophy, religion, and ethics, where there is no obvious way to verify or confirm correct answers perhaps it makes more sense to think researchers can hold to competing fundamental frameworks. In scientific research where confirmation is possible researchers must share enough common assumptions to have what Fogelin calls "normal" disagreements. In other words, where a subject's truth-content is confirmable, deep disagreement won't occur between researchers.

This response is false. The paradigm shifts that occur in science are not possible if scientists always share fundamental frameworks

\footnotetext{
${ }^{22}$ It's worth noting that if opponents fail to remain steadfast they will not discover that their disagreement is deep and will fail to gain the epistemic benefits. Also, if they don't remain steadfast, they will not be able to discover whether their dispute about $\mathrm{F}$ is (possibly) rationally resolvable.

(c) Kirk Lougheed. Informal Logic, Vol. 38, No. 2 (2018), pp. 263-292.
} 
(Kuhn 2012). Consider the highly controversial work of biologist Michael J. Behe. He believes that certain biochemical structures are irreducibly complex and hence are best explained by intelligent design rather than the theory of natural selection $(2006 ; 2008)$. While Behe's work has hardly been met with universal praise, it seems unfairly question-begging to dismiss his work on the basis that he isn't really a scientist. A better explanation is simply that Behe holds to different fundamental framework propositions from almost every other evolutionary biologist. ${ }^{23}$ To say he doesn't work within the same research context as other scientists would require providing necessary and sufficient conditions for what constitutes a biology research context which seems like an unreasonably difficult task.

\section{b. Agents with different frameworks aren't peers}

A related objection is the worry that it is impossible for two agents with different fundamental framework propositions to be epistemic peers. $^{24}$ Two agents with different framework propositions will understand the world in such different terms that it makes little sense to think of them as evidential and cognitive equals. For instance, Behe's views are so different from those of other biologists who accept evolution that we can't sensibly call Behe and his opponent's epistemic peers. However, it is possible to have a minimalist conception of peerhood which can obtain between two agents with different fundamental framework propositions and yet is strong enough to generate conciliationist pressure. Two agents with different frameworks can be epistemic peers if they are equally

\footnotetext{
${ }^{23}$ One might suggest that I have inadvertently offered an objection to the Benefits to Deep Disagreement Argument. Doesn't the argument license the work of someone like Behe as epistemically beneficial when it has little claim to rationality? I don't believe this is an objection even if it provides some rational support for researchers like Behe. Evolutionary theorists may be prompted to interact with Behe's work and this could lead them to better explicate their own views, etc. Even if Behe is wrong, the research community may indeed benefit from having him around. Note too that if this disagreement isn't the result of deep disagreement, the Benefits to Inquiry Argument still applies to it.

${ }^{24} \mathrm{I}$ 'm grateful to an anonymous referee for bringing this objection to my attention.

(C) Kirk Lougheed. Informal Logic, Vol. 38, No. 2 (2018), pp. 263-292.
} 
likely to be right (or wrong) with respect to whether $P$. An even simpler account says that two agents ought to treat each other as epistemic peers if they don't have reason to believe that one of them is more likely to be correct with respect to whether $P$. Provided that one admits that agents with different fundamental framework propositions can attempt to answer the same question (i.e., explore the truth-value of the same propositions) then this conception of peerhood is intelligible.

\subsection{The Scope of Argument}

It's an open question as to the scope of the Epistemic Benefits of Deep Disagreement Argument. Page has speculated that if cognitive diversity is somehow dependent on personal identity diversity, then there is an epistemic argument in support of personal identity diversity. This is interesting because most arguments in support of personal identity diversity are moral as opposed to epistemic. If fundamental frameworks are somehow connected to personal identity such that personal identity is responsible for inquiry beliefs then I have offered epistemic reasons in support of personal identity diversity, at least within research contexts. I make no claim as to whether this is in fact true. The truth of this is ultimately subject to empirical scrutiny.

Finally, can the argument be applied to beliefs or fundamental framework propositions outside of research contexts? Of course, the motivation for situating the argument firmly within research contexts is that it is easier to see how the epistemic benefits can be obtained in such cases. Inasmuch as non-inquiry related beliefs impact inquiry related beliefs then perhaps they fall within the confines of the argument. Inasmuch as all of the interconnected beliefs within fundamental framework propositions cause the inquiryrelated beliefs of an agent then perhaps those beliefs, and hence the entire set of framework propositions, fall within the scope of the argument. But it would be difficult to see how a non-inquiry belief on its own could be protected by what I've argued for here. Again, I take it that these claims are ultimately subject to empirical scrutiny. As it stands, I don't have the requisite information to judge the 
scope of Benefits to Inquiry Argument or the Benefits of Deep Disagreement Argument.

\section{Conclusion}

The epistemology of disagreement literature and argumentation theory have typically operated independently of one another. In the first part of this paper I developed a novel argument against conciliationism. An agent $S$ is rational to continue to believe proposition $P$ within research context $R$ in the face of epistemic peer disagreement if she reasonably believes there are epistemic benefits to be gained from believing $P$. Fogelin provocatively argues that disagreements between fundamental framework propositions are not susceptible to rational resolution. Rather than evaluating Fogelin's claim, I argued that inasmuch as fundamental framework propositions are responsible for an agent's inquiry-related beliefs, then disagreements over fundamental framework propositions are epistemically beneficial. These epistemic benefits obtain regardless of whether deep disagreements are susceptible to rational resolution. There are many examples of epistemic benefits resulting from individuals remaining steadfast in the face of intense peer disagreement. Rejecting this argument also means failing to recognize the distinction between synchronic reasons and diachronic reasons. Finally, it's an open question how far the argument can extend beyond research contexts. Inasmuch as personal identity is responsible for inquiry beliefs then I have offered an epistemic argument in support of identity diversity. The answer to this and related questions are ultimately subject to empirical scrutiny.

Acknowledgements: Thanks to Nathan Ballantyne, Nicholas Griffin, Klaas J. Kraay, Jonathan Matheson, Graham Oppy, and Robert Mark Simpson. Thanks also to the two anonymous referees at Informal Logic. Earlier versions of this paper were presented at the Summer School in Social Epistemology organized by the Social Epistemology Research Group (Copenhagen) held at Autonomous University of Madrid (August 2017), and at the Graduate Student work in progress group at Monash University (July 2014). This paper was made possible, in part, by funding from the Social Sciences and Humanities Research Council of Canada.

(C) Kirk Lougheed. Informal Logic, Vol. 38, No. 2 (2018), pp. 263-292. 


\section{References}

Adams, David M. 2005. "Knowing when disagreements are deep" Informal Logic 25(1): 65-77.

Ballantyne, Nathan. 2014. "Counterfactual philosophers." Philosophy and Phenomenological Research 88(2): 368-387.

Behe J. Michael. 2006. Darwin's black box: The biochemical challenge to evolution. New York: Free Press.

Behe J. Michael. 2008. The edge of evolution: The search for the of limits of darwinism. New York: Free Press.

Bergmann, Michael. 2009. "Rational disagreement after full disclosure." Episteme: A Journal of Social Epistemology 6: 336-353.

Billig, M. 1996. Arguing and thinking: A rhetorical approach to social psychology. Cambridge U.P.

Blinder, A.S. \& J. Morgan. 2000. "Are two heads better than one? An experimental analysis of group vs. Individual decision making." Working Paper 2909, National Bureau of Economic Research. Princeton, N.J.

Christensen, David. 2007. "Epistemology of disagreement: The good news." Philosophical Review 116(2): 187-217.

Christensen, David. 2014. "Disagreement and public controversy." In Essays in Collective Epistemology, eds. Jennifer Lackey, 142-162. Oxford U.P.

Crisp, R.J. \& R.N. Turner. 2011. "Cognitive adaptation to the experience of social and cultural diversity." Psychological bulletin, 137:2.

Davson-Galle, Peter. 1992. "Arguments, arguing, and deep disagreements" Informal Logic 14(2): 147-156.

Dessalles, J-L. 2007. Why we talk: The evolutionary origins of language. Oxford U.P.

Downs, Robert B. 1982. Landmarks in Science: Hippocrates to Carson. Littleton, Colo.

Duarte, J. L., Crawford, J. T., Stern, C., Haidt, J., Jussim, L., \& Tetlock, P. E. (2015). "Political diversity will improve social psychological science." Behavioral and Brain Sciences, 38: e130.

Elga, A. 2007. "Reflection and disagreement." Noûs, 41(3): 478-502.

Elgin, C. 2010. "Persistent disagreement." In Disagreement, eds. Richard Feldman \& Ted A. Warfield, 53-68. Oxford U.P.

Feldman, R. 2005. "Deep disagreement, rational resolutions, and critical thinking" Informal Logic 25(1): 13-23.

Feldman, R. 2007. "Reasonable religious disagreements." In Philosophers Without Gods, eds. Louise Antony, 194-214. Oxford U.P. 
Fiske, S.T., Harris, L.T., and A.J.C. Cuddy. 2004. "Why ordinary people torture enemy prisoners." Science, 1482-1483.

Friemann, R. 2005. "Emotional backing the feeling of deep disagreement" Informal Logic 25(1): 51-63.

Fogelin, R. J. 1985 [2005]. "The logic of deep disagreements" Informal Logic. 7(1): 1-8

Kelly, T. 2005. "The epistemic significance of disagreement." In Oxford Studies in Epistemology, eds. John Hawthorne and Tamar Szabó Gendler, 167-196. Oxford University Press.

Kelly, T. 2010. "Peer disagreement and higher order evidence." In Disagreement, eds. Richard Feldman and Ted A. Warfield, 111-174. Oxford U.P.

King, Nathan L. (2012). "Disagreement: What's the problem? or A good peer is hard to find." Philosophy and Phenomenological Research 85(2): 249-272.

Kuhn, Thomas. 2013. The structure of scientific revolutions. University of Chicago Press.

Lackey, Jennifer. 2010a. "What should we do when we disagree?" In $O x$ ford Studies in Epistemology, eds. Tamar Szabo Gendler \& John Hawthorne, 274-293. Oxford U.P.

Lackey, J. 2010b. “A justificationist view of disagreement's epistemic significance.” In Social Epistemology, eds. Adrian Haddock, Alan Millar, and Duncan Pritchard. Oxford U.P.

Laughlin, P.R., Bonner, B.L. \& Minder, A.G. 2002. "Groups perform better than the best individuals on letters-to-numbers problems." Organizational Behavior and Human Decision Processes 88(2): 605620.

Laughlin, P.R., Hatch, E.C., Silver, J.S. \& Boh, L. 2006. "Groups perform better than the best individuals on letter-to-numbers problems: Effects of group size." Journal of Personality and Social Psychology 90(4): 644-51.

Laughlin, P.R., Zander, M.L., Knievel, E.M. \& Tan, T.S. 2003. "Groups perform better than the best individuals on letter-to-numbers problems: Informative equations and effective reasoning." Journal of Personality and Social Psychology, 85(4): 684-694.

Lombardelli, C., Proudman, J. \& Talbot, J. 2005. “Committees versus individuals: An experimental analysis of monetary policy decisionmaking." International Journal of Central Banking, 1(1): 181-205.

Lougheed, K. "All-Thing-Considered Epistemic Rationality and Avoiding the Sceptical Consequences of the Equal Weight View." Unpublished Manuscript. 
Lougheed, K. 2017. "The Role of Idealized Cases in the Epistemology of Disagreement." Southwest Philosophy Review, 33(2): 251-270.

Lougheed, K. \& R.M. Simpson. 2017. "Indirect Epistemic Reasons and Religious Belief. Religious Studies, 53(2): 151-169.

Lugg, Andrew. 1986. "Disagreement and informal logic: No cause for alarm" Informal Logic 8(1): 47-51.

Matheson, J. 2015a. The Epistemic Significance of Disagreement. New York: Palgrave Macmillan.

Matheson, J. 2015b. "Disagreement and the ethics of belief." In The future of social epistemology: a collective vision, eds. James H Collier, 139148. USA: Rowman and Littlefield.

Memedi, V. 2007. Resolving deep disagreement. In H.V. Hansen, et. al. (Eds.), Dissensus and the Search for Common Ground, CD-ROM (pp. 1-10). Windsor, ON: OSSA.

Mercier, H., \& Sperber, D. 2011. Why do humans reason? Arguments for an argumentative theory. Behavioral and brain sciences, 34(2): 57-74.

Mercer, H., Sperber, D. 2017. The Enigma of Reason. Harvard U.P.

Michaelsen, L.K., Watson, W.E. \& Black, R.H. (1989). "A realistic test of individual versus group consensus decision making." Journal of Applied Psychology 74(5): 834-839.

Moscovici, C \& Personnaz, B. 1980. "Studies in social influence: V. Minority influence and conversion behavior in a perceptual task." Journal of Experimental Social Psychology 16(3): 270-282.

Moshman, D \& Molly Geil. 1998. "Collaborative reasoning: Evidence for collective rationality." Educational Psychology Papers and Publications 52: 231-248.

Nemeth, C.M. 1995. "Dissent as driving cognition, attitudes, and Nemeth, C., Brown, K. \& Rogers, J. 2001. "Devil's advocate versus authentic dissent: Stimulating quantity and quality." European Journal of Social Psychology, 31(6): 707- 720.

Page, S. 2007. The difference: How the power of diversity creates better groups, firms, and societies. USA: Princeton U.P.

Perelman, C. \& Olbrechts-Tyteca, L. 1969. The new rhetoric: A treatise on argumentation. University of Notre Dame Press.

Phillips, D. 2008. "Investigating the shared background requirement for argument: A critique of Fogelin's thesis on deep disagreement" Informal Logic 28(2): 86-101.

Siegel, Harvey (2013). Argumentation and the epistemology of disagreement. In Virtues of Argumentation. Proceedings of the 10th International Conference of the Ontario Society for the Study of Argumenta- 
tion (OSSA), eds. Mohammed, D., \& Lewiński, M., 22-26 May 2013. Windsor, ON: OSSA, pp. 1-22.

Sniezek, J.A. \& Henry, R.A. 1989. "Accuracy and confidence in group judgment." Organizational Behavior and Human Decision Processes 43(1): 1-28.

Sperber, D., Clément, F., Heintz, C., Mascaro, O., Mercier, H., Origgi, G., \& Wilson, D. 2010. Epistemic vigilance. Mind \& Language 25(4): 359-393

Sperber, D. 2000. "Metarepresentations in an evolutionary perspective." In Metarepresentations: A multidisciplinary perspective, eds. Dan Sperber, 117-137. Oxford U.P.

Sperber, D. 2001. "An evolutionary perspective on testimony and argumentation." Philosophical Topics 29: 401-413.

Sosa, E. 2010. "The epistemology of disagreement." In Social Epistemology, eds. Alan Haddock, Adrian Millar \& Duncan Pritchard, 278-297. Oxford University Press. [First published in 2009. Episteme 6(3): 269-279.]

Stasson, M.F., Kameda, T., Parks, C.D., Zimmerman, S.K. \& Davis, J.H. 1991. "Effects of assigned group consensus requirement on group problem solving and group members' learning." Social Psychology Quarterly 54(1): 25-35.

Surowiecki, J. 2004. The wisdom of crowds: Why the many are smarter than the few and how collective wisdom shapes business, economies, societies, and nations. USA: Random House, Inc.

Tindale, R.S. \& Sheffey, S. 2002. "Shared information, cognitive load, and group memory." Group Processes \& Intergroup Relations 5(1): 518.

Turner, Dale \& Larry Wright. (2005). "Revisiting deep disagreement" Informal Logic 25(1): 25-35.

Wittgenstein, Ludwig. 1972. On Certainty. Harper Perennial.

Zoltán, Imre. (Accessed August 21, 2014). "Ignaz Philipp Semmelweis," in Encyclopaedia Britannica Online Academic Edition. 